\title{
ARCHIVO \\ La tradición artesana de Colmenar de Oreja (Madrid)
}

Los vecinos del pueblo madrileño de Colmenar de Oreja realizaron en siglos pasados una importante y sorprendente actividad artesanal. Además de aquellos oficios más necesarios como los relacionados con la alimentación (panaderos, molineros de aceite, molineros de harina, etc.), con el vestido (sastres, zapateros, etc.), con la actividad agrícola (carreteros, herreros, herradores, cabestreros, jalmeros, cedaceros, etc.) y con la construcción (albañiles, tejeros, carpinteros, etc.), hubo también artesanos que practicaron trabajos menos frecuentes como los caldereros, alfareros, cereros, boteros, curtidores, tejedores de lana, lino, cáñamo y esparto, canteros y tinajeros.

La época de apogeo de la artesanía de Colmenar de Oreja fue la segunda mitad del siglo XviII y a ese período vamos a referirnos.

En 1753 había 62 panaderos que surtían no sólo a los vecinos de la población sino también a los de las proximidades como los de Chinchón, Valdelaguna y Villaconejos.

Funcionaban también 34 molinos de aceite.

Los cuatro alfares que existían entonces pertenecían a Antonio de Loro, José Canero, Tomás de Guadalajara y Bernardo y Diego de Loro. Fabricaban cántaros y otros objetos de barro vidriado en las cuatro hornadas que cocían al año cada uno de ellos.

Un francés nacido en Bearne llamado Pedro Salanave, instaló en Colmenar a mediados de siglo una fábrica de velas de sebo "que competían por blancura y duración con las de cera de Venecia " ${ }^{1}$. En 1780 regentaban la fábrica dos hijos de Salanave que obtenían diariamente 40 arrobas de velas.

En las cinco tenerías de la población se elaboraban suelas, cordobanes y badanas de calidad. Trabajaban en ellas tres maestros curtidores y tres oficiales, un maestro zurrador con dos oficiales y dos aprendices y varios pelaires. Los dueños de las tenerías eran vecinos de Colmenar de Oreja: Manuel Rodríguez y Juan Martínez, Jesusa y Presentación de Torres, Luis Martínez, Juan de Salas y Antonia de Soria. Existían también 48

1 Interrogatorio de Lorenzana: Colmenar de Oreja, Archivo Diocesano de Toledo. 
noques o estanques donde se reblandecían las pieles. Los fabricantes de curtidos estaban exentos del pago de tributos concejiles, alcabalas y cientos por Reales Cédulas de 1748 y 1753.

El tejido de la lana tuvo en Colmenar de Oreja bastante importancia. Se empleaba como materia prima no sólo la que proporcionaba el ganado ovino de la población sino también la que adquirían los tejedores en Morata de Tajuña, Perales de Tajuña, Valdaracete y Villamanrique de Tajo.

A mediados del siglo XviII había 16 telares de paños que ya llevaban trabajando bastante tiempo. Estaban atendidos por once maestros y once oficiales. Hasta unos años antes habían gozado los fabricantes de exención de oficios y cargas concejiles, alojamiento de tropas, etc., por Real Cédula de 29 de junio de 1731. Todos esos beneficios los perdieron al disminuir la calidad de los paños. Después, el número de telares fue aumentando y en 1778 había ya 30 que elaboraban "paños ordinarios, estameñas y albornoces" ${ }^{2}$.

La rubia, hierba cuya raíz era utilizada como materia tintórea para los paños, era abundante, de buena calidad y se daba en estado silvestre en el término de Colmenar de Oreja. Había dos molinos dedicados a moler la rubia.

Junto al río Tajo funcionaba el batán donde eran golpeados y batidos los paños para enfurtirlos y desengrasarlos.

Hubo también tejedores que utilizaban el cáñamo que se cultivaba en el pueblo y el lino que se adquiría en otros lugares. Obtenían un lienzo casero de buena calidad que usaban no sólo los vecinos de Colmenar sino los de los pueblos próximos.

El esparto fue una materia textil muy utilizada en otros tiempos para elaborar una serie de productos especialmente empleados en los medios rurales como cuerdas, ramales, sogas, serones, espuertas, etc. El tejido del esparto se realizó antiguamente en muchos pueblos madrileños pero de una forma especial en los situados al este de la provincia, donde es más abundante esa planta. Se realizaba esa actividad generalmente de forma temporal, en épocas de paro agrícola y como medio de procurarse unos recursos necesarios por la pobreza existente en aquellos tiempos. A mediados del siglo XviII en Colmenar de Oreja 150 esparteros se ocupaban de hacer sogas ${ }^{3}$ : "....muchos vecinos se aplican a coger esparto, cuando no tienen que ganar el jornal, y hacen sogas torcidas, en que se ocupan no sólo ellos sino sus familias".

2 Tomás LóPEZ, Diccionario geográfico, Manuscrito de la Biblioteca Nacional.

3 Catastro de Ensenada: Colmenar de Oreja, Archivo Histórico Provincial de Toledo. 
Unos años después la dedicación a esa actividad había aumentado y los productos obtenidos se utilizaban en bastantes lugares de España ${ }^{4}$ : "Produce gran cantidad de esparto que se emplea en labrar como la cuarta parte del vecindario, hilando a mano lo que llaman liñuelo y torciendo soga que vienen a comprar de toda Castilla la Vieja y otras muchas partes".

La población de Colmenar de Oreja era entonces de 1.200 vecinos. Las canteras de Colmenar proporcionan una piedra caliza compacta, porosa y de gran belleza que resiste bien y sin agrietarse al paso del tiempo. Se ha empleado en la construcción de importantes edificios como el Palacio Real, el Palacio de Aranjuez, el Banco de España, el Museo del Prado, el Observatorio Astronómico, la Puerta de Alcalá, etc. También ha servido esa piedra para la realización de grandes obras escultóricas. En 1753 trabajaban en Colmenar 28 canteros que transportaban la piedra empleando muchos bueyes y carretas. Uno de ellos, Francisco Checa, empleaba diez parejas de bueyes en diez carretas. José Carrillo utilizaba nueve. Otros canteros como Gabriel Ufano, Manuel de Ribas, José Canova y Alfonso Ruiz tenían cuatro o cinco carretas cada uno. Había también en esa época siete vecinos que, sin ser canteros, se dedicaban a transportar piedra a diversos lugares, especialmente a Madrid y a Aranjuez, durante la época en que "andaban corrientes las canteras", es decir en primavera y verano.

Entre todos los oficios que hubo en Colmenar de Oreja destacó el de la fabricación de tinajas de gran calidad, cuyos orígenes sin duda son muy antiguos.

En la época a que nos estamos refiriendo, en la que ya se había producido una decadencia de esa industria, buena parte de los vecinos de la población estaban relacionados de forma directa o indirecta con esa actividad.

Funcionaban entonces ocho hornos que pertenecían a varios maestros tinajeros de la localidad, algunos de ellos formando sociedad:

1. Eusebio París y Andrés de Encinas

2. Manuel González

3. Manuel París y Manuela Zazo

4. Pedro Romero

5. José de la Cámara

6. María Merino

7. Felipe Ruiz y Alfonso Casero

8. María López

4 Tomás LóPEZ, op. cit., pp. 311-315. 
En 1778 las tinajas de Colmenar de Oreja seguían gozando de buena fama y se vendían en toda España ${ }^{5}$ : "Entre todas las fábricas y maniobras de esta villa, la más acreedora a llevarse las atenciones es la de las tinajas, de donde sacan y llevan para toda la península y aun para embarcarlas; en cuya labor y formación y primor se ocupa notable parte de sus moradores fabricando anualmente de 150.000 a 170.000 arrobas de cabidam.

Unos años después las tinajas fabricadas en esta población se consideraban aún las mejores de España por su tamaño y duración ${ }^{6}$ :

...cuya obra les cuesta nada menos que todo un año de fatiga en sacar la tierra de la mina, en prepararla, colarla, batirla y formar a mano sin torno, molde ni otro auxilio cada una, haciéndose algunas de enorme tamaño de más de 400 arrobas de cabida, logrando sacarlas todas por su destreza, cuidado, buen material y perfecto temple en el horno, de una duración tan asombrosa que sólo un golpe puede romperlas, pero los años no logran consumirlas. En dos o tres pueblos de España que han emprendido su construcción, no han conseguido tales tamaños ni firmeza, sacándolas de aquí para toda la Península, aún para embarcarlas.

En las diversas operaciones necesarias para fabricar las tinajas participaban bastantes personas.

Además de la gran variedad de actividades artesanales que se desarrollaron en Colmenar de Oreja, nos llama la atención la importante participación femenina en ellas, en una época en que la intervención de la mujer en la industria era muy escasa.

Tenemos numerosos testimonios de escritores de esa época sobre la falta de vocación de las mujeres españolas para la artesanía. Rodríguez Campomanes escribió a propósito de esto ${ }^{7}$ :

Las mujeres deberían ocuparse en muchos oficios que emplean hombres. Esa mayor ventaja sacaría el Estado de su sexo cuyos individuos viven en gran parte sin modo de ganar recogidamente el sustento. Tal es el bordado y muchos géneros de tejidos, algunos ramos de la sastrería y otras varias cosas para que tienen mayor disposición que los hombres y más facilidad de aprenderlas a que debe agregarse la preparación de muchas primeras materias. La preocupación de ver casi ociosas las mujeres en algunas provincias del Reino no es una razón sólida que autorice su inacción. Es una perniciosa desidia que conviene desarraigar.

5 Tomás LÓPEZ, op. cit., pp. 311-315.

6 Interrogatorio de Lorenzana: Colmenar de Oreja, Archivo Diocesano de Toledo.

7 Pedro Rodríguez CAMPOMANES, Discurso sobre la educación popular de los artesanos y su fomento (Madrid, 1978), p. 183. 
Larruga y Boneta escribió también sobre la falta de afición de las mujeres madrileñas a participar en los trabajos artesanos ${ }^{8}$ :

Así en las mujeres como en los hombres de esta provincia se halla bella disposición para ser útiles al Estado por medio de la industria, pero su indolencia los tienen inclinados a la ociosidad y con particularidad a las mujeres, que si se exceptúan las que vienen a establecerse de otras provincias, con dificultad se hallan quienes sepan hacer una media bien hecha.

En el Diccionario Geográfico de Tomás López se critica a las mujeres del pueblo madrileño de Quijorna por su falta de actividad ': "Las mujeres aquí carecen enteramente de todo oficio, no se hila ni se cose, ni se hace media ni calceta; lo único coser la ropa del marido. Estos ciernen la harina y masan el pan".

También en el Interrogatorio de Lorenzana se censura con dureza la falta de participación de las mujeres de varias poblaciones madrileñas en los oficios artesanos, como vemos en estos ejemplos ${ }^{10}$. Rozas de Puerto Real: "Debía de haber telares de aflueques reforzados y terciados para ocupar a las mujeres, las cuales, después de haber hilado dos o tres meses en el invierno, andan ociosotas buscando con los hijos a cuestas como pasar el tiempo en los carasoles y mentideros".

Hoyo de Manzanares: "Las mujeres son tan poco aplicadas como ellos".

Es cierto que en varios pueblos madrileños las mujeres realizaron un importante papel en algunas formas de artesanía. En Fuencarral y Miraflores de la Sierra, por ejemplo, se dedicaron a tejer bastante lana y lino. En los telares de jerga de Fuenlabrada trabajaron mujeres. En Alcorcón eran éstas generalmente las encargadas de aplicar a los objetos de barro el alcor o sulfuro de plomo para vidriarlo, lo que les producía dolores en el pecho.

En Colmenar de Oreja hubo una importante intervención femenina en varios de los oficios que allí existieron.

Bastantes mujeres se dedicaron al hilado y tejido de lana en los distintos telares que funcionaron.

También tejieron lienzos caseros de buena calidad empleando cáñamo, sobre todo, y lino ${ }^{11}$ : "El sexo femenino se compite domésticamente a hilar y tejer mucho cáñamo y algún lino, fabricando lienzo casero de excelente calidad para más de su gasto".

8 Eugenio LARRUGa BONETA, Memorias políticas y económicas sobre los frutos, comercio, fábricas y minas de España (Madrid, 1787-1800), I, p. 12.

9 Tomás LÓPEZ, op. cit., pp. 311-315.

10 Interrogatorio de Lorenzana: Colmenar de Orjea, Archivo Diocesano de Toledo.

11 Tomás LOPEZ, op. cit., pp. 311-315. 
El tejido del esparto fue en Colmenar de Oreja una ocupación familiar en la que la mujer realizaba un papel importante, superando a veces a los hombres por su habilidad.

Dos de las cinco tenerías que funcionaban entonces eran propiedad de mujeres, como hemos visto. La casi totalidad de los 48 noques pertenecían en esos años a mujeres.

También dos personas de ese sexo eran dueñas de dos de los ocho hornos de tinajas.

Algunas de estas formas de artesanía de la segunda mitad del siglo XviII seguían existiendo en el siglo pasado y en los primeros años del actual.

En 1850 seguía funcionando uno de los telares de paños ordinarios y se tejía bastante esparto.

El trabajo de las canteras entró en decadencia desde principios de este siglo al emplearse menos la piedra en la edificación.

La piedra de Colmenar, por su belleza y calidad, se ha seguido utilizando para importantes obras. El empleo de maquinaria moderna permite el trabajo en la cantera a cielo abierto y el aprovechamiento de los fragmentos como grava en las carreteras y como componente de abonos, piensos compuestos, etc. si son sometidos a una molienda intensa.

Siguieron fabricándose tinajas durante el siglo XIX y a finales del mismo tuvo un nuevo florecimiento esa industria en Colmenar de Oreja. Llegaron a trabajar 32 hornos, de ellos 29 en pleno funcionamiento.

Vivían entonces de la fabricación, acarreo, venta de leña para los hornos, etc., la quinta parte de la población que era en esos años de algo más de 1.700 vecinos ${ }^{12}$.

Los nombres de los tinajeros como José y Antonio González Valdeolivas, Jerónimo Mendieta, Francisco, José y Toribio Freire, Eugenio y Manuel Estecha, Ciriaco y Rufino González, Antonio Boto, Fermín Herrero, Ricardo Rodríguez, etc., podíamos verlos grabados en las tinajas por toda España hace unos años.

Este tipo de industria comenzó a decaer en los primeros años de nuestro siglo, al ser sustituida la tinaja tradicional de barro por otra de cemento, de mayor duración que aquella.

Hoy Colmenar de Oreja es una población moderna habitada por gentes emprendedoras, como lo fueron sus antepasados del siglo xviII.

ALEJANDRO PERIS BARRIO

12 Francisco DE PABlos y GostanZA, Colmenar de Oreja, Biblioteca de la Provincia de Madrid (Madrid, 1891), p. 54. 